\title{
Does load management using the acute:chronic workload ratio prevent health problems? A cluster randomised trial of 482 elite youth footballers of both sexes
}

\author{
Torstein Dalen-Lorentsen (10 , John Bjørneboe, ${ }^{1}$ Benjamin Clarsen 지 , ${ }^{1,2}$ \\ Markus Vagle, ${ }^{1,3}$ Morten Wang Fagerland, ${ }^{1}$ Thor Einar Andersen ${ }^{1,4}$
}

- Additional material is published online only. To view, please visit the journal online (http://dx.doi.org/10.1136/ bjsports-2020-103003)

'Oslo Sports Trauma Research Center, Department of Sports Medicine, Norwegian School of Sports Sciences, Oslo, Norway ${ }^{2}$ Department for Disease Burden, Norwegian Institute of Public Health, Bergen, Norway ${ }^{3}$ Department of Sports, Physical Education and Outdoor Studies, University of South-Eastern Norway, Horten, Norway ${ }^{4}$ Department of Sports Medicine, Aspetar Orthopaedic and Sports Medicine Hospital, Doha, Qatar

\section{Correspondence to}

Torstein Dalen-Lorentsen, Oslo Sports Trauma Research Center, Department of Sports Medicine, Norwegian School of Sports Sciences, Oslo, Norway: torstein.dalen@nih.no

Accepted 10 September 2020 Published Online First 9 October 2020

\begin{abstract}
Background The acute:chronic workload ratio (ACWR) is commonly used to manage training load in sports, particularly to reduce injury risk. However, despite its extensive application as a prevention intervention, the effectiveness of load management using ACWR has never been evaluated in an experimental study. Aim To evaluate the effectiveness of a load management intervention designed to reduce the prevalence of health problems among elite youth football players of both sexes.

Methods We cluster-randomised 34 elite youth football teams ( 16 females, 18 males) to an intervention group (18 teams) and a control group (16 teams). Intervention group coaches planned all training based on published ACWR load management principles using a commercially available athlete management system for a complete 10-month season. Control group coaches continued to plan training as normal. The prevalence of health problems was measured monthly in both groups using the Oslo Sports Trauma Research Centre Questionnaire on Health Problems.

Results The between-group difference in health problem prevalence (primary outcome) was 1.8\%-points $(-4.1$ to $7.7 \%$-points; $p=0.55)$ with no reduction in the likelihood of reporting a health problem in the intervention group (relative risk 1.01 (95\% Cl 0.91 to 1.12); $p=0.84$ ) compared with the control group. Conclusions We observed no between-group difference, suggesting that this specific load management intervention was not successful in preventing health problems in elite youth footballers. Trial registration number ISRCTN18177140.
\end{abstract}

\section{INTRODUCTION}

Health problems are common among elite youth footballers who experience similar injury and illness patterns and burden as senior professional players. ${ }^{1-3}$

Previous studies in elite youth football have found that at any given time of the season, the prevalence of health problems is over $40 \% .^{3}$ Loss of participation due to health problems can negatively affect the players' performance, ${ }^{4}$ their health later in their career ${ }^{5}$ and, ultimately, their long-term development. ${ }^{7}$ Therefore, preventive measures are important.
A range of general and specific exercise-based interventions have shown substantial efficacy. ${ }^{8-15}$ In most cases, these interventions have been tested among elite adult male players ${ }^{8-10} 1315$ and recreational youth players ${ }^{12}{ }^{14}{ }^{16}$; only one study has been performed on elite youth players. ${ }^{17}$

Recently, researchers and practitioners have increased their interest in training load as a risk factor for health problems in football, ${ }^{18}$ with numerous studies reporting an association between training load and injury. ${ }^{19-22}$ Consequently, training load monitoring and management has gained widespread popularity as a preventive measure in professional and elite youth football. ${ }^{18} 23$ There is currently no consensus on which training load parameters should be monitored, how their cutoff values should be set and how load progression should be evaluated. Moreover, load management is performed in numerous ways, is often dictated by the philosophy of the club staff or manager and has no consensus scientifically. ${ }^{1823}$ In 2014, Hulin et $a l^{24}$ proposed the concept of the acute:chronic workload ratio (ACWR), whereby an athlete's recent training load (acute workload) is divided by their training load over a longer period of time (chronic workload). This metric is suggested to aid practitioners in managing training load within certain ranges. $^{2526}$ The initial concept was based on avoiding sudden spikes in training load, trying to keep ACWR within an arbitrary 'optimal range' of $0.8-1.5 .^{2526}$

Observational evidence supporting an association between ACWR and injury is inconsistent and controversial, ${ }^{27-30}$ and there are no experimental studies to determine whether using ACWR to manage training loads actually prevents injury or illness. Therefore, the aim of this cluster randomised controlled trial was to assess the effect of an ACWR-based load management intervention on health problem risk among elite youth footballers of both sexes.

\section{METHODS}

This study involved 482 Norwegian elite U-19 football players (178 females, 278 males), conducted during a complete season from February to November 2018.

\section{Recruitment}

We identified 78 teams from the vicinity of members in our research group and their participation in one 


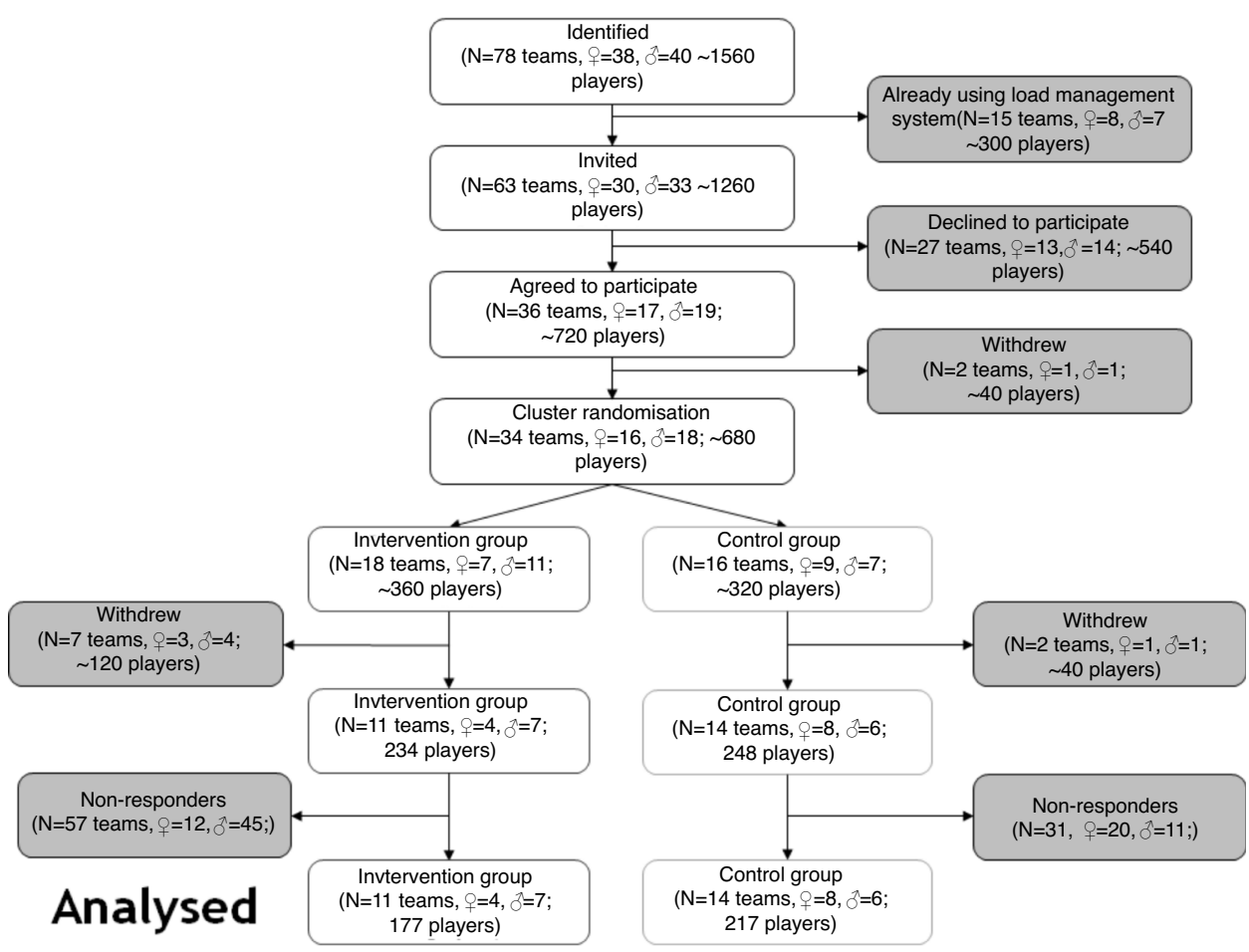

Figure 1 Flow of the teams and the players throughout the intervention.

of the top two tiers of Norwegian youth football. Of these, 15 teams that already used a training load management system were not invited, as this was likely to affect their adherence with the intervention. Sixty-three teams were invited and 27 declined to participate, 10 due to time constraints and 17 teams did not respond to the invitation or give any specific reason for why they declined (figure 1). Players who were permanent squad members were invited to participate in the study, with the exception of players who were likely to be absent from football training and match play for the study period due to severe health problems at baseline.

\section{Participants}

Thirty-six teams (15 females and 21 males) accepted the invitation to participate, and all players (or their guardian) on these teams gave their written consent to take part in the study (figure 1). The trail started for each team after all players had provided written consent, and the team had completed their introductory course to either the intervention group or the control group routines. Data collection was closed as each team finished their season.

\section{Randomisation}

We randomised on a team level to minimise the risk of contamination bias between players within the teams. A statistician, blinded to the study protocol, computer-generated blocks of 4 and 6 teams in random order. After a team and their players agreed to participate, the principal investigator opened a sealed envelope revealing the team's group assignment.

\section{Blinding}

It was impossible to blind players, coaches or the principal investigator to group allocation. However, a research assistant decoded the outcome measures during the data collection period, and outcome measures were not available to any of the members of the study group until all data had been collected.

\section{Intervention}

The intervention consisted of individualised load management of every player in the intervention group. Intervention group coaches planned the weekly training plan (microcycle) based on each player's training load history. A commercially available athlete monitoring system (AMS; Athlete Monitoring, Fitstats Inc, New Brunswick, Canada) assisted coaches in planning player microcycles, based on ACWR theory. ${ }^{24}$ ACWR was calculated as the coupled 7-28 day ratio using a rolling average. We instructed the intervention group coaches on training load management theory and how to use the AMS to plan training content, duration and intensity. Each coach received a 1-hour introductory session and a follow-up session 2 weeks later if necessary. Coaches were instructed to follow a periodisation model based on the 'optimal range' concept described by Hulin et $a l,{ }^{24} 31$ where the aim was to progress or maintain player load while ensuring they remained within the desired ACWR range of $0.8-1.5$.

All training load data reported by the players were instantly available on the coach dashboard in the AMS (figure 2). After finishing all weekly football activity every Sunday evening, coaches reviewed and arranged the individual training plans for the following week. The coaches were expected to have detailed insight into all their players' planned training and match activities (including activities outside the club team, ie, high-school training, regional team and national team). The AMS combined the subsequent week's (7 days) planned training load with the training load from the past 21 days (a rolling average of 28 days) and calculated the planned ACWR for the subsequent week.

If the planned training activity in the subsequent week led to players having an ACWR below 0.8, the AMS alerted the coach with a suggestion to increase the load accordingly. Conversely, if the planned activity led to an ACWR above 1.5, the AMS alerted the coach (figure 3 ) and suggested that they decrease the planned load. Additionally, during the week, coaches were expected to ensure that players completed their training as planned and, if 


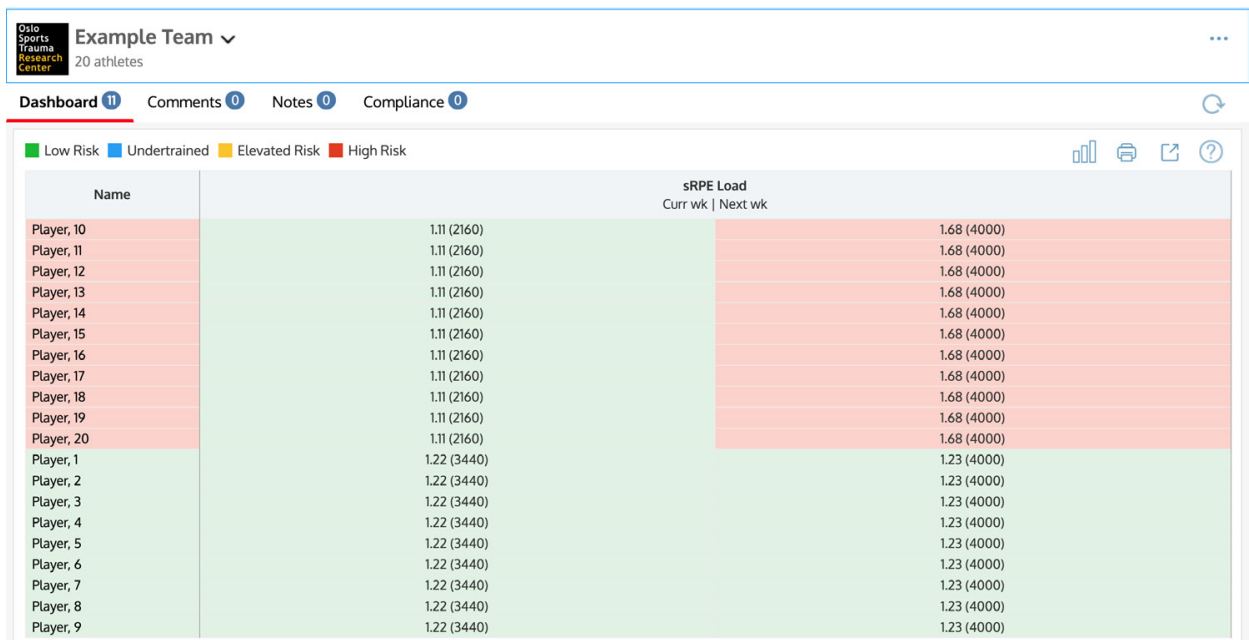

Figure 2 Coaches dashboard in the AMS after next week's training load is planned.

necessary, adjust the programme to keep them within the ACWR 'optimal range' (ie, if a player reported much higher loads than planned in the start of the week, the remainder of the weekly load could be reduced or vice versa).

We regularly contacted the coaches and sent supportive email each month to encourage them to continuing their training planning based on the intervention.

\section{Collection of training load data}

Intervention group players recorded the duration and their overall perceived rate of physical exertion (RPE) using the modified Borg CR-10 scale ${ }^{32}$ after all footballing activity, including non-organised football play. Players were familiarised with the collection method as well as the Borg scale before study start. We calculated an arbitrary training load unit (AU) by multiplying the duration with the session RPE (sRPE) ${ }^{32}$ for all football activities. Ten minutes after each training session was planned to be completed, a link to a questionnaire in the AMS smartphone app was sent to the players via an automated short message service (SMS; see online supplemental file 3 for details). If players had not replied to the questionnaire 12 hours postactivity, they received a second SMS, reminding them to complete the questionnaire. If players failed to complete the session questionnaire, the AMS treated the player as not being a part of the training and leaving a session value of nil in the calculations (and falsely decreasing the load of the player). The control group did not record any training load data.

\section{Collection of health data}

We used the Oslo Sports Trauma Research Centre Questionnaire on Health Problems (OSTRC-H2) Questionnaire (online supplemental file 1$)^{33}$ to record health data. Players responded to the questionnaire in the last week of each month and were instructed to report health problems for the previous 7 days only, giving us weekly prevalence of 10 intervals at approximately 1 month apart.

The questionnaire was distributed using an online survey software (Briteback AB, V.2.5.3.1; Norrköping, Sweden) via SMS on Sunday at 21:00. Non-responders received an SMS reminder the following morning at 08:00. Players were asked to report all complaints, irrespective of their consequences on football participation or their need to seek medical attention, including illness and injury. ${ }^{34}$ If players answered anything but the lowest score (ie, 'no problem') on either of the questions, a health problem was registered. If a player registered alternative two or higher (ie, moderate or severe reduction, or inability to participate) in question 2 (training volume) or 3 (performance), the health problem was registered as substantial. Each month, we calculated

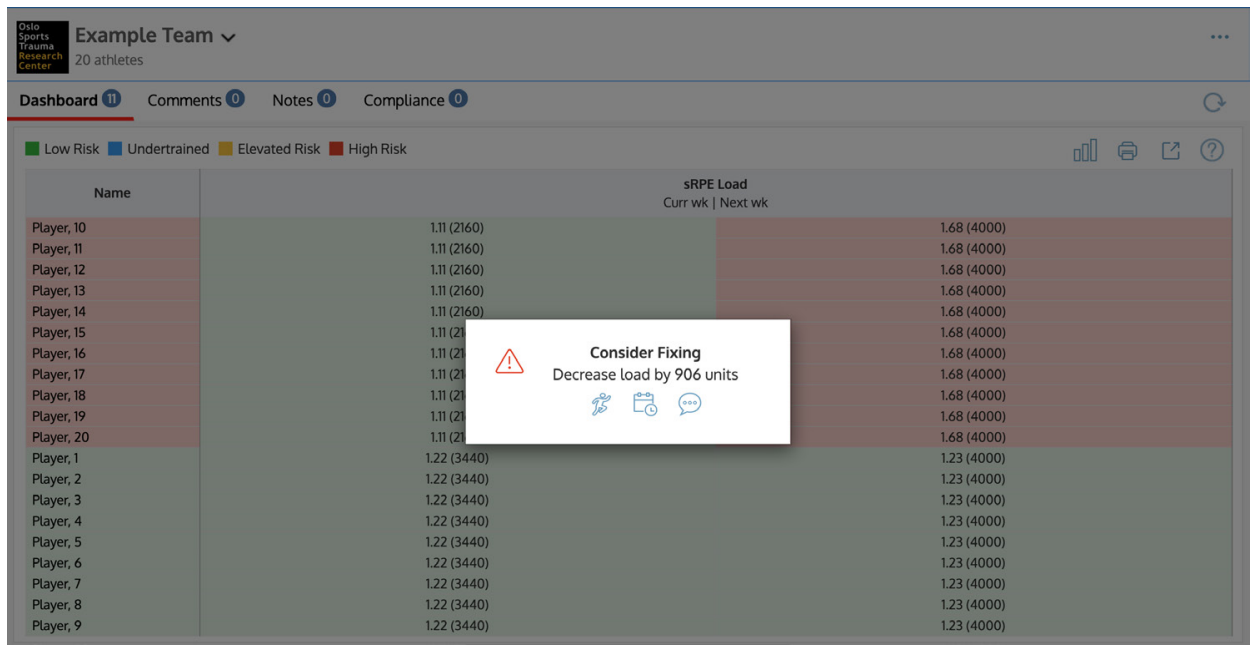

Figure 3 Coaches' dashboard in AMS suggesting a revision of planned load. AMS, athlete management system. 
prevalence of both outcomes by dividing the number of players reporting either a health problem or a substantial health problem to the total number of respondents in each group. To ensure consistent reporting of all health problems, we familiarised players with the definitions in the prestudy meeting and repeatedly emphasised the importance of reporting all health problems during the study period, irrespective of their consequences. We informed the players that the coaches and other club staff members did not have access to any health data.

\section{Outcome measures}

The primary outcome measure was the occurrence of all health problems over the course of the season. The secondary outcome measure was occurrence of substantial health problems over the course of the season.

\section{Statistical methods}

The primary effect measure was the between-group difference in prevalence (intervention - control). The secondary effect measure was relative risk (RR) ratio (intervention/control). To evaluate the effectiveness of the intervention, we fitted generalised estimating equations panel data models to the two outcomes: all health problems and substantial health problems. The models were defined with a binomial family, a log-link function and an exchangeable correlation matrix. The estimated SEs were adjusted for clustering, and a Kauermann and Carroll bias-corrected variance estimator, ${ }^{35}$ which is specifically recommended for cluster randomised trials, was used. The models included terms for group (intervention vs control) and time, and we report the results for group as the RR of intervention versus control. Initial models also included a term for group $\times$ time interaction; however, this term did not impact the models $(p=0.44$ for all health problems; $p=0.34$ for substantial health problems), and we removed the interaction term to obtain a simple and easily interpretable estimate of the intervention effect. We used the xtgeebcv command ${ }^{36}$ in Stata (V.15.3 StataCorp LLC, College Station, Texas, USA; see online supplemental file 2 for script and results). No attempt to impute missing training or health data was performed. All analyses were performed according to the intention-to-treat (ITT) principle, using a full analysis set definition; that is, we included all available data and analysed the teams as randomised. Teams that withdrew from the study directly after randomisation were excluded, as were players who did not record any outcome data.

\section{Sample size}

The sample size calculation was based on an average prevalence of health problems among elite youth footballers of $40 \%{ }^{3}$ Based on an analysis of variance of within-subject and withinteam prevalence, an inflation factor (DE) of 1.65 (to account for randomisation at the cluster level), a cluster size of 20 players, a power of $80 \%$ and a $5 \%$ significance level $(\alpha)$, we estimated that a sample of $2 \times 380$ players would be needed to detect a $40 \%$ reduction in prevalence. This was based on previous studies with a similar design ${ }^{837}$ and on our estimation of what coaches would consider a worthwhile meaningful difference. To find the inflation factor, the following formula was used $\mathrm{DE}=1+(\mathrm{n}-1)$ $\mathrm{p}$, where $\mathrm{n}$ is the number of individuals and $\mathrm{p}$ is the intracluster correlation coefficient. $^{38}$

\section{Ethics}

The study was registered in the International Standard Randomised Controlled Trial Number Registry.

\begin{tabular}{lcc}
\hline Table 1 & Baseline characteristics of players included in the analyses \\
\hline & Intervention group & Control group \\
\hline N & 177 & 217 \\
Girls & 57 & 107 \\
Boys & 120 & 110 \\
Age & $17.2(1.2)$ & $17.4(1.1)$ \\
\hline
\end{tabular}

\section{RESULTS}

\section{Participants}

A total of 34 teams were enrolled in the study; nine teams withdrew shortly after randomisation, and 88 players did not respond to any of the health problems questionnaires. Eleven teams in the intervention group and 14 teams in the control group completed the study, and the total number of players analysed was 394 (table 1).

The flow of the teams and the number of players are shown in figure 1. Of the nine teams that withdrew after randomisation, seven teams were randomised to the intervention group and two teams to the control group. The reasons stated for withdrawal from the intervention group were: wanted to be in the control group $(n=4)$, wanted to implement a different load management routine $(n=2)$ and change of coaching staff $(n=1)$. The two teams that withdrew from the control group indicated that they would rather be in the intervention group.

\section{Questionnaire response rate}

We recorded a total of 2475 health problems questionnaires. The compliance to the OSTRC-H2 questionnaire was $62 \%$ (range 10\%-100\%) in the intervention group and 76\% (range $10 \%-100 \%)$ in the control group, which amounts to an average of $69 \%$. The intervention group coaches planned a total of 25 004 player sessions and received 15253 player responses, which amounts to an overall response of 74\% (range $0 \%-100.0 \%$ ) to the post-training questionnaire.

\section{Training data}

The intervention group players' median weekly sRPE was 1470 (IQR 750) AU.

\section{Adherence with the intervention}

In a poststudy survey, the intervention group coaches replied to the following question describing their compliance with the intervention: did you use the AMS to plan training every week throughout the season? Eight out of 11 coaches responded and five replied 'yes, every week', two replied 'no, every other week' and one replied 'no, every month'.

\section{Primary outcome: all health problems}

The average prevalence of health problems was $65.7 \%(61.1 \%$ $70.2 \%)$ in the intervention group and $63.8 \%(60.0 \%-67.7 \%)$ in the control group (figure 4). The prevalence was $1.8 \%$-points $(-4.1$ to $7.7 \%$-points; $\mathrm{p}=0.55)$ higher in the intervention group, and there was no reduction in the likelihood of reporting a health problem in the intervention group (RR 1.01 (95\% CI 0.91 to 1.12$) ; \mathrm{p}=0.84$ ) compared with the control group.

\section{Secondary outcome: substantial health problems}

The average prevalence of substantial health problems was $31.1 \%(26.7 \%-35.5 \%)$ in the intervention group and $35.3 \%$ $(31.6 \%-39.1 \%)$ in the control group (figure 5$)$. The prevalence was $4.1 \%$-points $(-1.6$ to $9.9 ; \mathrm{p}=0.15)$ higher in the control 


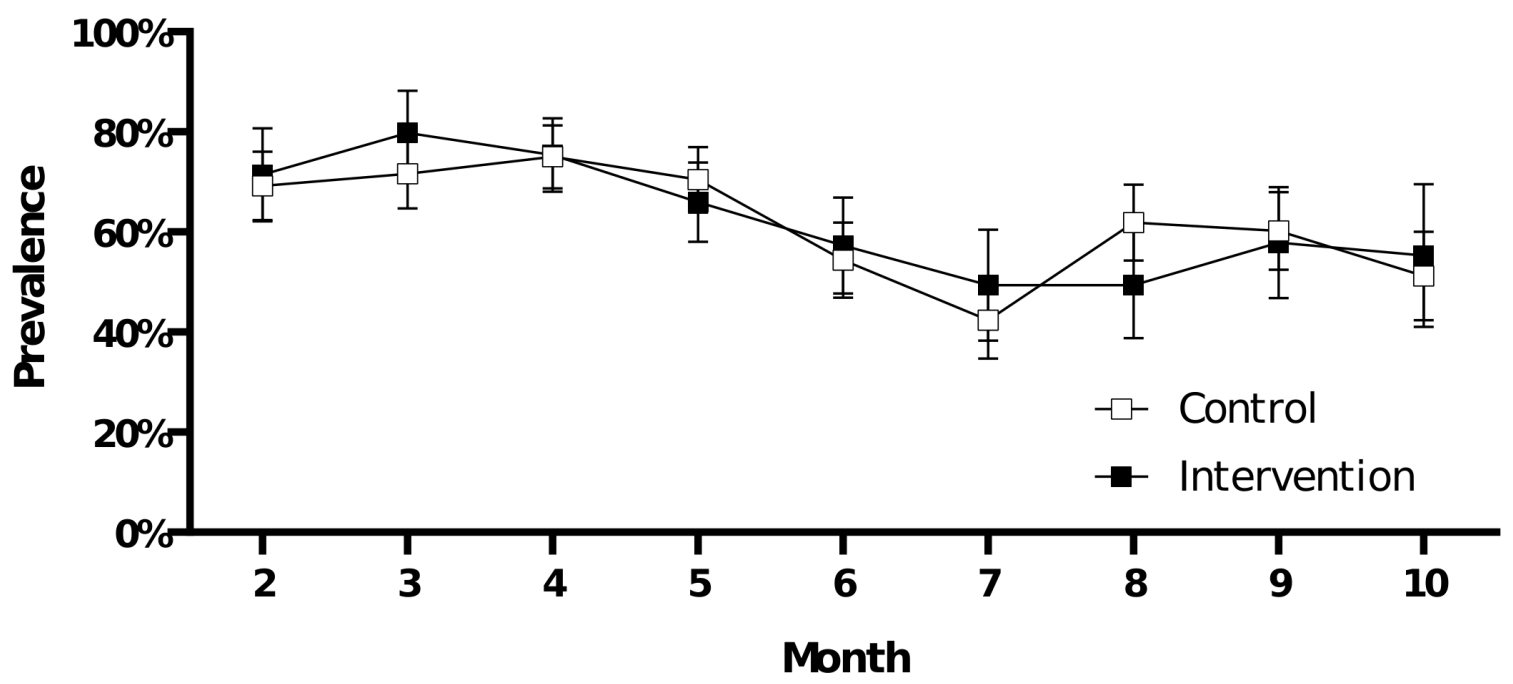

Figure 4 Prevalence of health problems in the control group and the intervention group throughout the season.

group, and there was no reduction in the likelihood of reporting a substantial health problem (RR $0.88(0.72$ to 1.06$) ; \mathrm{p}=0.17)$ in the intervention group compared with the control group.

\section{DISCUSSION}

This is the first randomised controlled trial investigating the effect of individual management of training loads on the risk of health problems in any sport. We did not identify any significant differences in either outcome between the intervention group and the control group.

\section{Intervention}

When planning this study, choosing the exact mode of intervention represented a major challenge. We were guided by the literature at the time, as well as the recommendations from the group that developed the ACWR approach. ${ }^{24} 2639$ Also, we considered what was commonly used in the field and therefore had the most practical relevance.

Since then, there has been increased scrutiny of the ACWR concept, with several papers highlighting methodological challenges $^{3040-45}$ and some authors questioning the validity of the entire concept. ${ }^{27-29}$ Despite many studies showing an association, no study has yet managed to predict health problems based on ACWR, ${ }^{20}$ indicating that a meaningful and pronounced relationship between ACWR and health problems is unlikely.

We tested the preventive effect on health problems by using one particular approach of load management. However, there is no consensus on which load management concept should be used or, if using ACWR, how it should be calculated. ${ }^{30}$ Our intervention was a one-size-fits-all approach, as we considered it to be the most feasible method for the coaches and because a structured individual protocol remains in a conceptual phase. ${ }^{46}$ Moreover, at the time we planned the study, the available literature recommended that a similar threshold should be used for all players. ${ }^{24}$ This one-size-fits-all approach has recently been challenged by both scientists and practitioners, as the relationship between ACWR and health problems is affected by a large number of individual moderating factors. ${ }^{46}$

Our training load parameter was sRPE. We chose sRPE as it is considered a valid method for measuring training load across various sports ${ }^{47}$ and for elite youth footballers specifically. ${ }^{48}$ Moreover, sRPE was the most practical way to quantify load in 25 non-professional youth football teams, and the majority of previous ACWR studies have used sRPE as their primary measure of load. ${ }^{19} 202249-67$

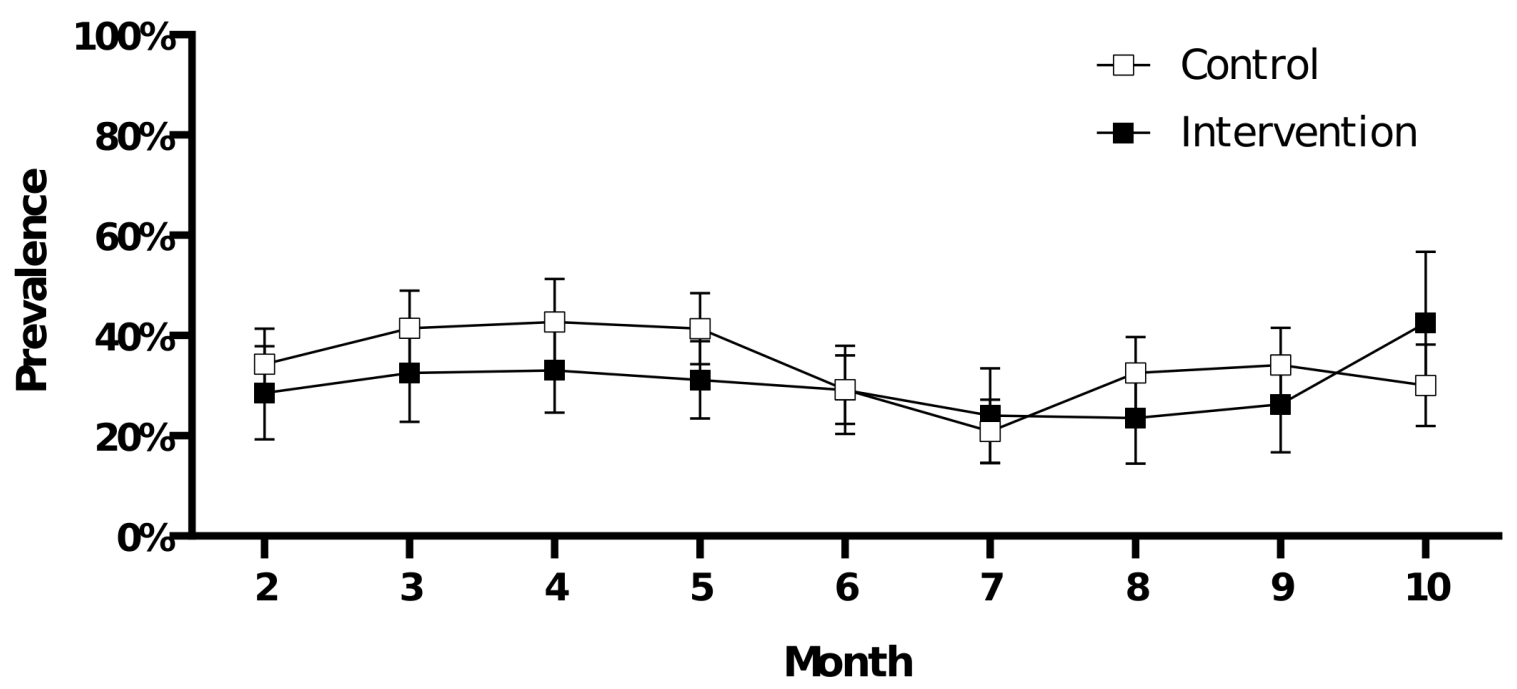

Figure 5 Prevalence of substantial health problems in the control group and the intervention group throughout the season. 


\section{Methodological considerations}

This study involved an intervention that was arguably more technically demanding and time-consuming for coaches and players than previous prevention studies in sports. ${ }^{837}$ These challenges may have led to reduced adherence to the intervention by the coaches and to reduced questionnaire response rates by the players.

A major limitation of the study is the method used to assess the coaches' adherence to the intervention. Ideally, we would have logs or questionnaires describing the extent to which their training planning was influenced by the ACWR, and how often they intervened in their players' training plan based on feedback from the AMS. However, we asked the coaches in a poststudy questionnaire where they indicated that, to a large extent, the intervention had been followed.

Another problem we faced was the health problem questionnaire average response rate of $69 \%$ and specifically the intervention group response rate of $62 \%$. One reason that the intervention group had lower response rate might be questionnaire fatigue, as they also reported training load after every football session. Moreover, as the AMS could not be used to collect the OSTRC-H2 at the time, the intervention group had to use two different systems to record training and health data, which is not optimal. Contrary to the health problem questionnaire, the training load questionnaire had a reasonably good response rate of $74 \%$, which might indicate that the AMS collected data in a more feasible way. Non-responders and non-compliances will introduce selection and measurement bias in our analyses and should be taken into consideration when interpreting our results. Despite some of the challenges with this method, using athlete-recorded health problems allowed us to use a broad health problem definition and thereby gain a more complete understanding of the range of health problems affecting the players. ${ }^{68} 69$ In particular, this broader approach was specifically designed to record overuse injuries, which are presumably the most preventable type of injury from a load management intervention. Nevertheless, this approach also has limitations. ${ }^{70}$ Health problems were not confirmed by a sports medicine practitioner or by diagnostic imaging, making our data less secure and detailed. Moreover, our approach includes illness as a health problem without knowing more specifically whether or to what extent the illness is caused by training load. If illness is not affected by training load, it might result a bias towards the null in our analyses. However, including illness is also a strength of the study as illness prevention is a favourable potential outcome of load management. ${ }^{71}$

The average prevalence of both health problems and substantial health problems are higher in our study than in previous studies. $^{38}$ The reason for this is unknown. However, as this finding was the same in both groups, we believe a betweengroup comparison is appropriate.

Choosing a suitable population is key when performing experimental research; elite youth players have previously been targeted in injury prevention research. ${ }^{17}$ We chose this cohort of athletes since many elite youth players in Norway train with and play for several different teams, making their load management challenging. Furthermore, this was deemed one of few cohorts where coaches systematically plan their training and, at the same time, where we would be allowed to influence their training content.

The modified ITT analysis could introduce selection bias due to the withdrawals postrandomisation and should be acknowledged as a limitation of the study.
We were unable to identify statistically significant differences between groups, a larger study with higher statistical powere might have found otherwise. In this case, and based on our CIs, the effect of the intervention would nonetheless be small to moderate.

\section{Perspectives}

Although many practitioners, researchers and players consider training load to be an important risk factor for health problems in football, supporting evidence is currently conflicting. To date, studies examining the relationship between training load and health problems have largely been descriptive studies.

This trial-the first randomised study in the field-demonstrates that, although difficult to conduct, it is not impossible. We hope, despite this study's methodological limitations, it will pave the way for future training load studies using a similar design.

In elite football, sports medicine and performance practitioners meticulously and continuously assess each player's training load together with numerous other factors, such as history of previous injuries, injuries, player age, wellness, non-sporting load, communication with player, screening and strength test and the importance of next match. This is done to inform subjective decisions that aim to increase performance and reduce risk of health problems. Providing coaches with a one-size-fits-all metric does not seem to add much value to this process. We believe that, given the results of this study and the current state of knowledge in the field, load management remains just as much an art as a science.

\section{CONCLUSION}

We provided coaches of teams in the intervention group with tools and knowledge to manage their players' training load using a common form of ACWR. This did not lead to a reduction in the prevalence of health problems, compared with teams in the control group. Managing training loads using ACWR does not appear to represent an effective prevention intervention in elite youth football.

\section{Patient and public involvement statement}

Coaches were involved in the design of the intervention and recruitment of teams and players to the study. Coaches and

Key messages

What are the findings?

- Load management using acute:chronic workload ratio (ACWR) in a one-size-fits-all approach does not appear to prevent health problems among elite youth football players of both sexes.

How might it impact on clinical practice in the future?

- The lack of a clear relationship between training load and health problems does not mean practitioners should abandon training load management. Its primary role has always been performance enhancement and not health problem prediction or prevention.

- With a lack of models linking training load and health problems, practitioners should follow the general training principles such as the principle of progressive overload.

- Alternative models of load management should be developed and their preventative effect tested. 
players were not involved in the design of the research questions, the outcome measures or the analyses. The results from the study will be disseminated to all teams that were included in the project.

Twitter Torstein Dalen-Lorentsen @torsteindalen, Benjamin Clarsen @benclarsen, Markus Vagle @markusvagle and Thor Einar Andersen @DocThorAndersen

Acknowledgements The authors are grateful to all the players and coaches who participated in the study. The authors would like to thank Rikke Kommedahl, Astrid Grøttå Ree, Gunvor Halmøy, Margareta Endresen, Michael Kleppen, Andreas Ranvik, Peder Lindsetmo and Margareta Endresen for participating in the data collection, as well as Roald Bahr, Lena Bache-Mathiesen and Eirik Halvorsen Wik for valuable feedback on the draft manuscript

Contributors TD-L, BC, TEA, JB and MWF planned the study. The data collection was done by TD-L and MV. All authors have been involved in the data analyses, drafting and revision of the manuscript, and all have approved the final version.

Funding The Oslo Sports Trauma Research Center has been established at the Norwegian School of Sport Sciences through generous grants from the Royal Norwegian Ministry of Culture, the South-Eastern Norway Regional Health Authority, the IOC, the Norwegian Olympic Committee and Confederation of Sport and Norsk Tipping AS.

Competing interests The Oslo Sports Trauma Research Centre has a research partnership together with Fitstats Inc. This partnership is based on the development of injury surveillance tools, which were not used in this study. Fitstats provided the use of athlete management system free for this study.

Patient and public involvement Patients and/or the public were involved in the design, or conduct, or reporting, or dissemination plans of this research. Refer to the Methods section for further details.

\section{Patient consent for publication Not required.}

Ethics approval The study was reviewed by the South-Eastern Norway Regional Committee for Medical and Health Research Ethics (2017/2232) and approved by the ethics board of The Norwegian School of Sports Sciences (39-1 91 217) and the Norwegian Center for Research Data (56935).

Provenance and peer review Not commissioned; externally peer reviewed.

Data availability statement All data relevant to the study are included in the article or uploaded as supplementary information. All data are available as supplementary files.

\section{ORCID iDs}

Torstein Dalen-Lorentsen http://orcid.org/0000-0003-4062-7601

Benjamin Clarsen http://orcid.org/0000-0003-3713-8938

\section{REFERENCES}

1 Jones S, Almousa S, Gibb A, et al. Injury incidence, prevalence and severity in highlevel male youth football: a systematic review. Sports Med 2019;49:1879-99.

2 Ekstrand J, Hägglund M, Waldén M. Injury incidence and injury patterns in professional football: the UEFA injury study. Br I Sports Med 2011;45:553-8.

3 Moseid $\mathrm{CH}$, Myklebust G, Fagerland MW, et al. The prevalence and severity of health problems in youth elite sports: a 6 -month prospective cohort study of 320 athletes. Scand J Med Sci Sports 2018:28:1412-23.

4 Røksund OD, Kristoffersen M, Bogen BE, et al. Higher drop in speed during a repeated sprint test in soccer players reporting former hamstring strain injury. Front Physiol 2017:8:00025

5 Maffulli N, Longo UG, Gougoulias N, et al. Long-Term health outcomes of youth sports injuries. Br J Sports Med 2010;44:21-5.

6 Fyfe JJ, Opar DA, Williams MD, et al. The role of neuromuscular inhibition in hamstring strain injury recurrence. J Electromyogr Kinesio/ 2013;23:523-30.

7 Ward P, Hodges NJ, Starkes IL, et al. The road to excellence: deliberate practice and the development of expertise. High Ability Studies 2007;18:119-53.

8 Harøy J, Clarsen B, Wiger EG, et al. The adductor strengthening programme prevents groin problems among male football players: a cluster-randomised controlled trial. $\mathrm{Br} J$ Sports Med 2019;53:150-7.

9 van der Horst N, Smits D-W, Petersen J, et al. The preventive effect of the Nordic hamstring exercise on hamstring injuries in amateur soccer players: a randomized controlled trial. Am J Sports Med 2015;43:1316-23.

10 Arnason A, Andersen TE, Holme I, et al. Prevention of hamstring strains in elite soccer: an intervention study. Scand J Med Sci Sports 2008:18:40-8.

11 van Dyk N, Behan FP, Whiteley R. Including the Nordic hamstring exercise in injury prevention programmes halves the rate of hamstring injuries: a systematic review and meta-analysis of 8459 athletes. Br J Sports Med 2019;53:1362-70.
12 Soligard T, Myklebust G, Steffen K, et al. Comprehensive warm-up programme to prevent injuries in young female footballers: cluster randomised controlled trial. BMJ 2008;337:a2469.

13 Whalan M, Lovell R, Steele JR, et al. Rescheduling Part 2 of the 11+ reduces injury burden and increases compliance in semi-professional football. Scand J Med Sci Sports 2019;29:1941-51.

14 Waldén M, Atroshi I, Magnusson H, et al. Prevention of acute knee injuries in adolescent female football players: cluster randomised controlled trial. $B M\lrcorner$ 2012;344:e3042

15 Mohammadi F. Comparison of 3 preventive methods to reduce the recurrence of ankle inversion sprains in male soccer players. Am J Sports Med 2007;35:922-6.

16 Steffen K, Emery CA, Romiti M, et al. High adherence to a neuromuscular injury prevention programme (FIFA 11+) improves functional balance and reduces injury risk in Canadian youth female football players: a cluster randomised trial. $\mathrm{Br}$ I Sports Med 2013:47:794-802.

17 Owoeye OBA, Akinbo SRA, Tella BA, et al. Efficacy of the FIFA 11+ warm-up programme in male youth football: a cluster randomised controlled trial. J Sports Sci Med 2014;13:321-8.

18 Akenhead R, Nassis GP. Training load and player monitoring in high-level football: current practice and perceptions. Int I Sports Physiol Perform 2016;11:587-93.

19 Delecroix B, McCall A. Workload and non-contact injury incidence in elite football players competing in European leagues. Eur J Sport Sci 2019;18.

20 Fanchini M, Rampinini E, Riggio M, et al. Despite association, the acute:chronic work load ratio does not predict non-contact injury in elite footballers. Science and Medicine in Football 2018;2:108-14.

21 Jaspers A, Kuyvenhoven JP, Staes F, et al. Examination of the external and internal load indicators' association with overuse injuries in professional soccer players. J Sci Med Sport 2017:1-7.

22 Malone S, Owen A, Newton M, et al. The acute:chonic workload ratio in relation to injury risk in professional soccer. J Sci Med Sport 2017;20:561-5.

23 Weston M. Training load monitoring in elite English soccer: a comparison of practices and perceptions between coaches and practitioners. Science and Medicine in Football 2018:2:216-24.

24 Hulin BT, Gabbett TJ, Blanch P, et al. Spikes in acute workload are associated with increased injury risk in elite cricket fast bowlers. Br J Sports Med 2014;48:708-12.

25 Blanch P, Gabbett TJ. Has the athlete trained enough to return to play safely? The acute:chronic workload ratio permits clinicians to quantify a player's risk of subsequent injury. Br J Sports Med 2016;50:471-5.

26 Gabbett TJ. The training-injury prevention paradox: should athletes be training smarter and harder? Br J Sports Med 2016;50:273-80.

27 Impellizzeri FM, Tenan MS, Kempton T, et al. Acute:Chronic Workload Ratio: Conceptual Issues and Fundamental Pitfalls. Int I Sports Physiol Perform 2020:907-13.

28 Impellizzeri FM, Woodcock S, Coutts AJ, et al. Acute to random workload ratio is 'as' associated with injury as acute to actual chronic workload ratio: time to dismiss ACWR and its components. SportRxiv 2020.

29 Impellizzeri FM, Woodcock S, McCall A, et al. The acute-chronic workload ratio-injury figure and its 'sweet spot' are flawed. SportRxiv 2019.

30 Dalen-Lorentsen T, Andersen TE, Bjørneboe J, et al. A cherry tree ripe for picking: The relationship between the acute:chronic workload ratio and health problems. SportRxiv 2020.

31 Hulin BT, Gabbett TJ, Lawson DW, et al. The acute:chronic workload ratio predicts injury: high chronic workload may decrease injury risk in elite rugby league players. $\mathrm{Br}$ J Sports Med 2016:50:231-6.

32 Foster C, Florhaug JA, Franklin J, et al. A new approach to monitoring exercise training. J Strength Cond Res 2001;15:109-15.

33 Clarsen B, Rønsen O, Myklebust G, et al. The Oslo sports trauma research center questionnaire on health problems: a new approach to prospective monitoring of illness and injury in elite athletes. Br I Sports Med 2014;48:754-60.

34 Fuller CW, Ekstrand J, Junge A, et al. Consensus statement on injury definitions and data collection procedures in studies of football (soccer) injuries. Br I Sports Med 2006;40:193-201.

35 Kauermann G, Carroll RJ. A note on the efficiency of sandwich covariance matrix estimation. J Am Stat Assoc 2001:96:1387-96.

36 Gallis JA, Li F, Turner EL. xtgeebcv: a command for bias-corrected sandwich variance estimation for Gee analyses of cluster randomized trials. Stata J 2020;20:363-81.

37 Andersson SH, Bahr R, Clarsen B, et al. Preventing overuse shoulder injuries among throwing athletes: a cluster-randomised controlled trial in 660 elite handball players. Br J Sports Med 2017:51:1073-80.

38 Rutterford C, Copas A, Eldridge S. Methods for sample size determination in cluster randomized trials. Int J Epidemiol 2015:44:1051-67.

39 Soligard T, Schwellnus M, Alonso J-M, et al. How much is too much? (Part 1) International Olympic Committee consensus statement on load in sport and risk of injury. Br J Sports Med 2016;50:1030-41.

40 Lolli L, Batterham AM, Hawkins R, et al. Mathematical coupling causes spurious correlation within the conventional acute-to-chronic workload ratio calculations. $\mathrm{Br}$ 」 Sports Med 2019;53:921-2. 
41 Lolli L, Batterham AM, Hawkins R, et al. The acute-to-chronic workload ratio: an inaccurate scaling index for an unnecessary normalisation process? Br J Sports Med 2019;53:098884.

42 Sampson JA, Fullagar HHK, Murray A. Evidence is needed to determine if there is a better way to determine the acute:chronic workload. Br J Sports Med 2017;51:621-2.

43 Williams S, West S, Cross MJ, et al. Better way to determine the acute:chronic workload ratio? Br J Sports Med 2017;51:096589-3.

44 Andrade R, Wik EH, Rebelo-Marques A, et al. Is the acute: chronic workload ratio (ACWR) associated with risk of Time-Loss injury in professional team sports? A systematic review of methodology, variables and injury risk in practical situations. Sports Med 2020;50:1613-35.

45 Wang C, Vargas JT, Stokes T, et al. Analyzing Activity and Injury: Lessons Learned from the Acute:Chronic Workload Ratio. Sports Med 2020;50:1243-54.

46 Bittencourt NFN, Meeuwisse WH, Mendonça LD, et al. Complex systems approach for sports injuries: moving from risk factor identification to injury pattern recognitionnarrative review and new concept. Br J Sports Med 2016;50:1309-14.

47 Haddad M, Stylianides G, Djaoui L, et al. Session-RPE method for training load monitoring: validity, ecological usefulness, and influencing factors. Front Neurosci 2017;11:612.

48 Impellizzeri FM, Rampinini E, Coutts AJ, et al. Use of RPE-based training load in soccer. Med Sci Sports Exerc 2004;36:1042-7.

49 Ahmun R, McCaig S, Tallent J, et al. Association of daily workload, wellness, and injury and illness during Tours in international cricketers. Int I Sports Physiol Perform 2019:14:369-77.

50 Carey DL, Blanch P, Ong K-L, et al. Training loads and injury risk in Australian footballdiffering acute: chronic workload ratios influence match injury risk. Br J Sports Med 2017;51:096309

51 Colby MJ, Dawson B, Peeling P, et al. Multivariate modelling of subjective and objective monitoring data improve the detection of non-contact injury risk in elite Australian footballers. J Sci Med Sport 2017;20:1068-74.

52 Cross MJ, Williams S, Trewartha G, et al. The influence of In-Season training loads on injury risk in professional rugby Union. Int J Sports Physiol Perform 2016:11:350-5.

53 Esmaeili A, Hopkins WG, Stewart AM, et al. The individual and combined effects of multiple factors on the risk of soft tissue non-contact injuries in elite team sport athletes. Front Physiol 2018;9:1280.

54 Harrison PW, Johnston RD. Relationship between training load, fitness, and injury over an Australian rules football Preseason. J Strength Cond Res 2017:31:2686-93.

55 Jaspers A, Brink MS, Probst SGM, et al. Relationships between training load indicators and training outcomes in professional soccer. Sports Medicine 2016:1-12.
56 Johnston R, Cahalan R, Bonnett L, et al. Training load and baseline characteristics associated with new Injury/Pain within an endurance sporting population: a prospective study. Int I Sports Physiol Perform 2019;14:590-7.

57 Lathlean TJH, Gastin PB, Newstead SV, et al. Absolute and relative load and injury in elite junior Australian football players over 1 season. Int I Sports Physiol Perform 2019:1-9.

58 Lu D, Howle K, Waterson A, et al. Workload profiles prior to injury in professional soccer players. Science and Medicine in Football 2017:1:237-43.

59 Malone S, Roe M, Doran DA, et al. Protection Against Spikes in Workload With Aerobic Fitness and Playing Experience: The Role of the Acute:Chronic Workload Ratio on Injury Risk in Elite Gaelic Football. Int J Sports Physiol Perform 2017;12:393-401.

60 McCall A, Dupont G, Ekstrand J. Internal workload and non-contact injury: a oneseason study of five teams from the UEFA elite Club injury study. Br J Sports Med 2018;52:1517-22.

61 O'Keeffe S, O'Connor S, Ní Chéilleachair N. Are internal load measures associated with injuries in male adolescent Gaelic football players? Eur J Sport Sci 2020;20:249-60.

62 Pote L, Christie CJ. Workloads placed on adolescent cricket players: a pilot study. Int J Sports Sci Coach 2019;14:107-13.

63 Raya-González J, Nakamura FY, Castillo D, et al. Determining the relationship between internal load markers and noncontact injuries in young elite soccer players. Int $\mathrm{J}$ Sports Physiol Perform 2019;14:421-5.

64 Stares J, Dawson B, Peeling P, et al. Identifying high risk loading conditions for inseason injury in elite Australian football players. J Sci Med Sport 2018;21:46-51.

65 Thornton HR, Delaney JA, Duthie GM, et al. Importance of various Training-Load measures in injury incidence of professional rugby League athletes. Int I Sports Physiol Perform 2017:12:819-24.

66 Weiss KJ, Allen SV, McGuigan MR, et al. The Relationship Between Training Load and Injury in Men's Professional Basketball Players. Int I Sports Physiol Perform 2017:1-20.

67 Watson A, Brickson S, Brooks A, et al. Subjective well-being and training load predict in-season injury and illness risk in female youth soccer players. Br J Sports Med 2017;51:194-9.

68 Clarsen B. Current severity measures are insufficient for overuse injuries. Science and Medicine in Football 2017;1:91-2.

69 Clarsen B, Bahr R. Matching the choice of injury/illness definition to study setting, purpose and design: one size does not fit all! Br J Sports Med 2014;48:510-2.

70 Orchard J, Hoskins W. For debate: consensus injury definitions in team sports should focus on missed playing time. Clinical Journal of Sport Medicine 2007;17:192-6.

71 Schwellnus M, Soligard T, Alonso J-M, et al. How much is too much? (Part 2) International Olympic Committee consensus statement on load in sport and risk of illness. Br J Sports Med 2016:50:1043-52. 